\title{
Supporting the Competent Practitioner: Trans-disciplinary Coaching with a Knowledge-Based Expert System
}

\author{
Jolan Velencei ${ }^{1}$, Zoltan Baracskai ${ }^{2}$, Viktor Dorfler ${ }^{3}$, Marc Stierand ${ }^{4}$ \\ ${ }^{1}$ Associate Professor of Decision Support, Obuda University, Budapest, Hungary, \\ ${ }^{2}$ Professor of Coaching \& Decision Making, Babes -Bolyai University, Cluj-Napoca, Romania, \\ ${ }^{3}$ Senior Lecturer in Information \& Knowledge Management, University of Strathclyde Business School, \\ Glasgow, UK \\ ${ }^{4}$ Assistant Professor of Service Management, École hôtelière de Lausanne, HES-SO // University of Applied \\ Sciences Western Switzerland, Lausanne, Switzerland
}

\begin{abstract}
The purpose of this paper is to describe the roles of the coach and the coachee from the perspective of their respective competences and a particular type of the coaching process that we call 'competent coaching'. We also show how this process can be supported with a knowledge-based expert system (KBS); to illustrate this, we introduce a particular knowledge-based expert system shell, Doctus, that can assist the coaching process. We also offer a set of concepts, organised into a conceptual framework, in order to help both coach and coachee to (re-)shape the coaching process and thus achieve greater contextual sensitivity. Our contribution is a multi-personal account, rooted in some 100 years of combined coaching experience and around four decades of researching and teaching coaching to business school students at the undergraduate, MBA and doctoral level, including executive education.
\end{abstract}

Keywords: Coaching, Knowledge-Based Expert Systems, Trans-disciplinary, Decision making

\section{Introduction}

The literature, predominantly textbooks in the Kuhnian (1962: 144) sense, is full of trivial definitions of coaching. 'The coaching is what the coach does' is one such example that never tells us who the coach actually is. Such trivial definitions are not only useless but dangerous as well. They are dangerous for two reasons: (1) they shroud the concept of coaching in a cloak of mystery, and (2) they often try to sell something else simply relabelled as coaching. The 'something else' can range from (analytical) consultancy work and market research to facilitation and even confidential chat companionship and public confessions 'Jeremy Kyle style'.

Yet, the process of coaching is highly complex with scholars frequently making use of metaphors in an attempt to achieve some level of intuitive understanding that scientific language cannot provide. Thus, for several years, we described coaching using football coaches as a metaphor (Baracskai, Dorfler \& Velencei): They yell, flail, and run up and down the football pitch trying to make their team win without ever striking the ball themselves. Senge et al (1999: 108-109) have perhaps provided the most insightful description of coaching so far using a comparison between golf and polo coaches. "In golf coaching, there's plenty of time to reflect on your previous performance and plan your next shot. You can even go back and retake the shot, just to see how to handle it differently.” But, polo coaching is different. "The little white ball no longer waits for you. It's always in motion. You no longer stand on firm ground; you carry a mallet and ride a galloping horse. Your teammates are also mounted on horses; and you have to coordinate your actions with them. Your opponents surround you, moving at fast speeds, and intent on knocking the ball away. Horse manure flies everywhere. And the coach remains far away from you, shouting advice from the side-lines that you probably can't even hear." Senge et al. further emphasise that coaching in organizations is even more complex than polo, 
because " $[t]$ he boundaries of the playing field keep changing. Every day, the game will be a little bit different, and probably a bit more difficult [...]. Coaching, in short, no longer takes place before the game or from the sidelines; it is a critical part of the game itself."

Hence, nobody would deny that competence is a sine qua non characteristic of any proper coach regardless of the discipline. In this paper, we therefore start from the premise that any coaching should be done by competent coaches regardless of whether the coachee is already competent or a novice on the road to becoming competent. What we call 'competent coaching', however, is a coaching process between a competent coach and a competent coachee. It is important to note that we do not mean to suggest that the coach is not a practitioner. In fact, the statements we make regarding the development of the practitioner, in the following sections of the paper, apply to the coach as well. Moreover, our propositions do not result from a systematic review or meta-analysis of the literature nor do they stem from an analysis of a particular data set purposely collected for this paper. Our propositions are the result of a multipersonal account, rooted in some 100 years of combined coaching experience and around four decades of researching coaches and coachees and teaching coaching to business school students at the undergraduate, MBA and doctoral level, including executive education. Through this multi-personal account, we describe the competent coach and the competent coachee, and the coaching process between them, which we are referring to as 'competent coaching' in this paper. We also show how this process can be supported with a knowledge-based expert system (KBS); particularly with our KBS shell, Doctus. We also offer a set of concepts, organized into a conceptual framework, in order to help both coach and coachee to (re-)shape the coaching process and thus achieve greater contextual sensitivity. In what follows, we first describe how our educational systems produce what we call the 'semi-specialized cultivated mind', which is the mind of the 'novice practitioner'. Subsequently, we follow the journey of the novice towards competence and explain why the competent practitioner invariably needs to have a 'trans-disciplinary mind'. Then we turn to the coach, examining how the competent coach differs from other competent practitioners in terms of trans-disciplinarity. Finally, we describe the process of competent coaching and how it can be supported with the Doctus KBS shell.

\section{Novice practitioner: The Cultivated Mind}

In today's world, disciplines, in both the hard sciences, such as physics or biology, and soft fields, such as the arts or psychology, have grown so vast that no single person could possibly master them anymore in their entirety. This means that nobody today fully masters physics or biology, and, similarly, nobody can fully grasp the field of psychology or economics. However, it is possible to get a taste of the various disciplines at every level of education, which typically starts with a liberal arts education. Elementary school pupils learn reading, arithmetics, swimming, painting and singing. In high school, they may learn how to solve integrals, burn sulphur, study the directions and timing of Napoleon's conquests or understand the necessary role of the antagonist in a story. At this phase, pupils start to specialise, shifting more towards hard or soft disciplines. At the university level, engineering students become familiar with the deep secrets of the Carnot-cycle and the Nash equilibrium but are usually no longer capable of understanding anything a sociology professor says and vice versa. The outcome of the university is then a 'semi-specialised cultivated mind'. By 'semi-specialised' we mean that it is not a balanced knowledge anymore, such as it was in the liberal arts phase, but engineers can still read, know some history, and some of them will appreciate paintings, others music.

The semi-specialised cultivated mind of the practitioner (Velencei, Baracskai \& Dorfler, 2015) is familiar with the main concepts of the discipline it has specialised in. In the formal education environment, these concepts are developed from scratch, which is a time-consuming process that includes the validation of these concepts in an intellectual context through thinking. This means that the cultivated mind sees the world through the lens of their respective disciplines and can think about it using the disciplinary (textbook) context. Then, however, the cultivated mind leaves the school and finds itself in the context of praxis. To their horror, the recent graduates find themselves in a place that seems familiar, i.e., the concepts are recognisable but seem to mean something different than what they are 'supposed' to mean. They quickly realise that textbook knowledge is largely useless, because - in order to gradually develop an understanding of the meaning of these concepts in praxis - the novice practitioner needs to re-develop them. This is another timeconsuming process, which includes the validation of these concepts in an applied context through doing. In other words, the understanding of the 'logic of praxis' can only be achieved through a "knowing-in-action" process, through which the novice practitioner gradually produces "repertoires of solutions" (Schon, 1983, 1987). Such a process follows the logic of 'artistry' (Cheetham \& Chivers, 1998: 267). According to Stierand and Zizka (2015: 353), it is a 
'bringing-together' of savoir (conceptual knowing), savoir-faire (knowing how to do things) and savoir-être (knowing how to be).

However, it would not be possible to develop a new understanding of any concepts, if the recent graduate did not have an understanding of these concepts in the first place. Therefore, we assert that formal education, which produces semispecialised cultivated minds, is both necessary and useless. It is necessary, because this is how practitioners learn to think according to the logic of their native disciplines. Though, at the same time, purely intellectual disciplinary education is also useless, because it does not enable novice practitioners to understand the contextually sensitive logic of praxis that is capable of masterfully manipulating textbook concepts. In this process of learning by doing (Anzai \& Simon, 1979), novice practitioners typically go back several times to the world of formal education to refresh their knowledge and learn new concepts of the discipline. Then, they bring this new knowledge and these new concepts back to praxis. Thus, it is through going back and forth between formal education and praxis that novice practitioners gradually develop into competent practitioners.

\section{Competent Practitioner: The Trans-disciplinary Mind}

A competent coach also needs a trans-disciplinary mind, but one that is somewhat different from the competent practitioner's trans-disciplinary mind. Being competent does not mean omniscient, i.e. competent practitioners do not know everything that there is to be known from their native disciplines, let alone from all of their adjunct disciplines. There is a simple reason for this: new knowledge is produced at a very fast pace and competent practitioners do not have the time to continuously scan the knowledge production landscape and examine all available knowledge that may be relevant. This very reason defines the need for and the role of the coach. Coaches do what practitioners do not have time for: they continuously scan the knowledge production landscape for new accessible knowledge. They do not scan all the available knowledge, only accessible knowledge endorsed by the gurus of the various domains (i.e. the leading thinkers of the respective domains, cf Prusak \& Davenport, 2003). The role of the gurus is not to create all new knowledge, they often validate knowledge created by others, and they validate new knowledge they like. Guru endorsement is important as coaches do not always have the time to examine in detail all accessible knowledge. This works if and when coaches are able to build a sense of trust about the knowledge endorsed by the guru.

Now, we can outline an initial conceptual framework for coaching (Figure 1). In this initial version we describe the knowledge with three qualities that correspond to the various stages of the coaching process. First, we have accessible knowledge, which means knowledge the coach has access to. Second, we have contextualised knowledge that is created in a process between coach and coachee; here we give a high-level description of the contextualisation and we will unpack this part in the next section. Finally, we have applied knowledge, that is, knowledge put to work. The three types of knowledge do not describe stages put forward as steps following each other in a linear manner, but should rather be understood as phases that are overlapping, iterative and nonlinear.

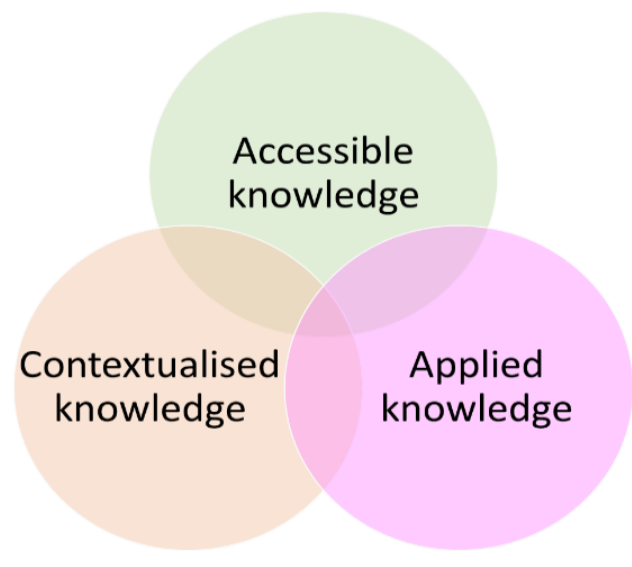

Figure 1: The initial conceptual framework of competent coaching 
According to our framework, the coach is continuously scanning accessible knowledge and will develop preferences based on personal taste and competence. This happens before the coach has met the coachee, often even before thinking about whether it could be of interest to an organisation such as a pharmaceutical company or a film studio. After having met the coachee for the first time in order to form a picture of the coachee's praxis problems, the coach, based on personal experience, examines whether any particular knowledge(s) he has scanned may be of interest to the coachee. Once the coach has identified accessible knowledge of potential interest, (s)he pitches it to the coachee for contextualisation. Coachees, though, usually cannot contextualise new knowledge by themselves. This means that the coach must be able to help the coachee contextualise the new knowledge in the context of the coachee's praxis. In turn, this requires that the coach makes use of adjunct disciplines that enable her/him to achieve sufficient understanding of the coachee's context so as to gain orientation and be able to communicate during the coaching process. This ability to participate in contextualising knowledge in somebody else's praxis shows that coaches need a trans-disciplinary mind, but one that is different from that of competent practitioners, for coaches' adjunct disciplines usually not only need to be more versatile, but often need to be what we call 'composite disciplines', disciplines that relate to, for example, problem areas or industries rather than to 'academic' disciplines. This is also the reason why coaches usually specialise in a few industries and/or problem areas - a coach who can coach in all industries and problem areas is probably illsuited to work in any of them. Finally, the implementation process may happen as part of the coaching or be conducted subsequently by the coachee's organisation without the participation of the coach; the applied knowledge is the result of the implementation.

\section{Competent Coaching: Using a Knowledge-based Expert System}

The coach usually chooses knowledge that either originates from any problem area in her/his native discipline, or from one of her/his adjunct disciplines in a problem area (s)he is familiar with. This selection process is essentially a sense making process (Weick, 1979, 1995) that is rigorous but not precise, i.e., it does not rely on definitions but follows the art of poetry: "Don't confuse rigor with exact definition. Too many definitions kill rigor, which is why poetic knowledge is more rigorous than scientific knowledge" (Nicolescu, 2016: 76). Hence, there is nothing methodologically sensible about how the competent coach identifies new knowledge that (s)he likes. Competent coaches also do this differently from one another, some of them have 'a method', most do not, but even those who do, do not follow it all the time. In this sense, this process shows characteristics of "indisciplinarity", a kind of anarchical state denying disciplines altogether and being deliberately anti-methodological (Nicolescu, 2014: 188). This works, because competence forms our intuitive expertise (Baracskai, Dorfler \& Velencei, 2005; Dorfler \& Ackermann, 2012; Dorfler \& Eden, 2014; Stierand, 2015; Stierand \& Dorfler, 2014, 2016).

Once the knowledge is identified, the competent coach 'brings' it to the competent practitioner (part 1 of the initial framework). The contextualisation that follows (part 2 of the initial framework) can perhaps most easily be understood as a validation process. There are three aspects of validation that need to be covered in the process of competent coaching (Dorfler, 2016); as this is done in a more or less fixed order, we identify them as phases of contextualisation (Figure 2): (1) We validate the consistency of the accessible knowledge; this relates to the notion of internal validity in research. In this phase, we try to make sense of the available knowledge and connections need to be made to the coachee's existing knowledge (Dorfler, 2010). (2) We examine the relevance of the consistent knowledge, which relates to the notion of construct validity in research. In this phase, the consistent knowledge needs to be connected to the decision at hand. (3) We examine the applicability of the relevant knowledge; which relates to the notion of external validity in research. In this phase, relevant knowledge is examined with reference to the particular decision alternatives in the particular context. 


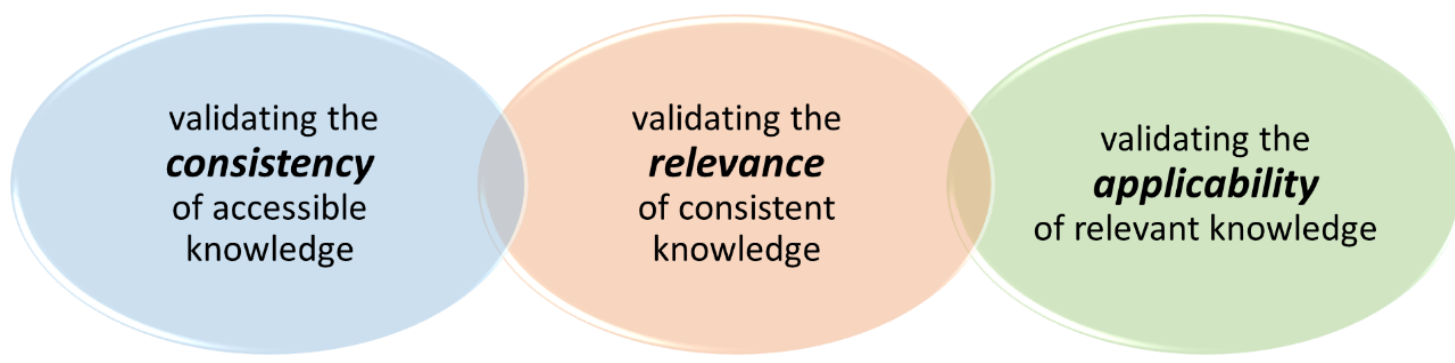

Figure 2: The three phases of validation (Source: Dorfler, 2016).

We call the process of contextualisation in competent coaching 'knowledge engineering' and make use of a knowledge-based expert system (KBS). It is useful for the competent coach to have a tool such as a KBS at her/his disposal, which can show the logical connections between the knowledge elements. We have developed our own KBS shell, 'Doctus', and we have been using it with coaching decision makers for 25 years now. Doctus is capable of three types of reasoning (Baracskai, Dorfler \& Velencei, 2007; Velencei et al., 2015), but here we only consider rule-based reasoning (RBR) as it is what we use in coaching. The other types of reasoning are used in different types of consultancy work. In terms of RBR, Doctus is similar to many other KBS shells with one notable exception: it has a fully graphical user interface. This means that in Doctus we do not need to build the knowledge base using Prolog or LISP codes, so using the software does not require any programming knowledge. For representing knowledge, we use 'if... then' rules - which competent practitioners usually find much easier to make sense of than of tables with probabilities, weights, scores, and other quantitative representations. Besides, the accessible knowledge brought to the table by the competent coach often cannot be described using a quantitative representation anyway.

Consistency: For validating consistency, the coachee describes the accessible knowledge in the form of attributes, values (for example, Colour: [yellow, red, blue, green, brown], Size: [small, large, gigantic]) and if... then' rules between the values of the attributes (for example, 'if the Colour is green and the Size is gigantic then'). The 'if... then' rules will also connect the accessible knowledge to the existing knowledge of the coachee. The software will flag any contradictions in the knowledge base that supports the work of the coach and the coachee. During this first phase, the coachee acquires the accessible knowledge through making sense of it, while the software shows how it connects to her/his existing knowledge. The knowledge base is not the accessible knowledge in itself but the representation of the 'new' knowledge of the coachee, which now contains the accessible knowledge as well (of course, not all knowledge of the coachee is represented, only what the accessible knowledge connects to). By the end of the consistency validation, i.e. when all the rules are entered and contradictions removed, the knowledge base becomes a kind of new entity in the knowledge space; at this point we have consistent knowledge.

Relevance: The second phase, the validation of relevance, starts when the initial knowledge base is ready. Then the coach guides the coachee to step back and look at the knowledge base as a whole — to see the 'big picture'. Although it is based on the coachee's knowledge, more often than not, the coachee will not immediately recognise this new entity in the knowledge space. There is a particularly interesting step in this process which often leads to what is usually called a 'knowledge discovery'. When expressing the 'if... then' rules, coachees typically formulate elementary rules (one value of each attribute in the particular node) or 'trivial' complex rules, such as 'if the Colour is green and the Size is gigantic, nothing else matters, it is unacceptable'. However, once all the rules are formulated, typically around 2,000-3,000 of them, the machine learning algorithm of the software compresses the rules into complex ones, achieving the smallest number of rules that can deliver what the coachee expressed. This will reduce the number of rules typically by order of magnitude. We often hear coachees say something along the lines of: 'I did not say this!' - but they did. Only they did not say it that way. It is fascinating to see as the coachees become acquainted with the knowledge representation they have created. This is usually when the most important learning happens, only this is not about learning something new, this is about learning something old. They did, in fact, know what they now see, only they did not know that they knew it. Once the coachees can accept the knowledge representation, which may involve several rounds of fine-tuning, the consistent knowledge has passed the validation of relevance: at this point we have 'relevant knowledge'. 
Applicability: The third phase, validating the applicability of the relevant knowledge, is done by applying the rules to particular decision alternatives. At this time, we encourage the coachees to suggest some good as well as bad alternatives; the knowledge base cannot be tested for applicability using only the best alternative or the worst one. The really tricky part is when the alternatives are 'sort of equally good' but different alternatives have different strengths and weaknesses. And, of course, these are not all expressed in dollars, pounds, euros and yens, so that we could easily convert between them. They are all expressed on qualitative scales that are ordinal (i.e. we know that green is better than yellow, but not by how much or how many times). Once the coachee is happy with all the outcomes, we conclude this validation, the knowledge is ready to be implemented: we have applicable knowledge at this point (not applied yet, it is only applied once the implementation is completed).

Of course, the process of contextualisation is not so neat and linear as we described here; there are usually numerous iterative cycles involved, although the logic remains the same. However, when, for instance, validating the relevance (second phase) of the knowledge, the coachee may find out that there is a problem with the consistency (first phase) this may result in adding new attributes, adding, removing or merging values, changing rules, etc. Similarly, when validating the applicability (third phase), we may go back and revise the relevance (second phase) or even the consistency (first phase), making further changes to the knowledge base or to the complex rules (without changing the elementary rules) or changing both. On rare occasions, sometimes we even look for new accessible knowledge, but this we regard as a new process starting from scratch. Figure 3 outlines a more refined conceptual framework of competent coaching. Essentially, it is developed by opening up the initial framework outlined in Figure 1, replacing the contextualisation with the three phases of validation from Figure 2, indicating the possible iterative cycles and adding the details of who participates in the particular part.

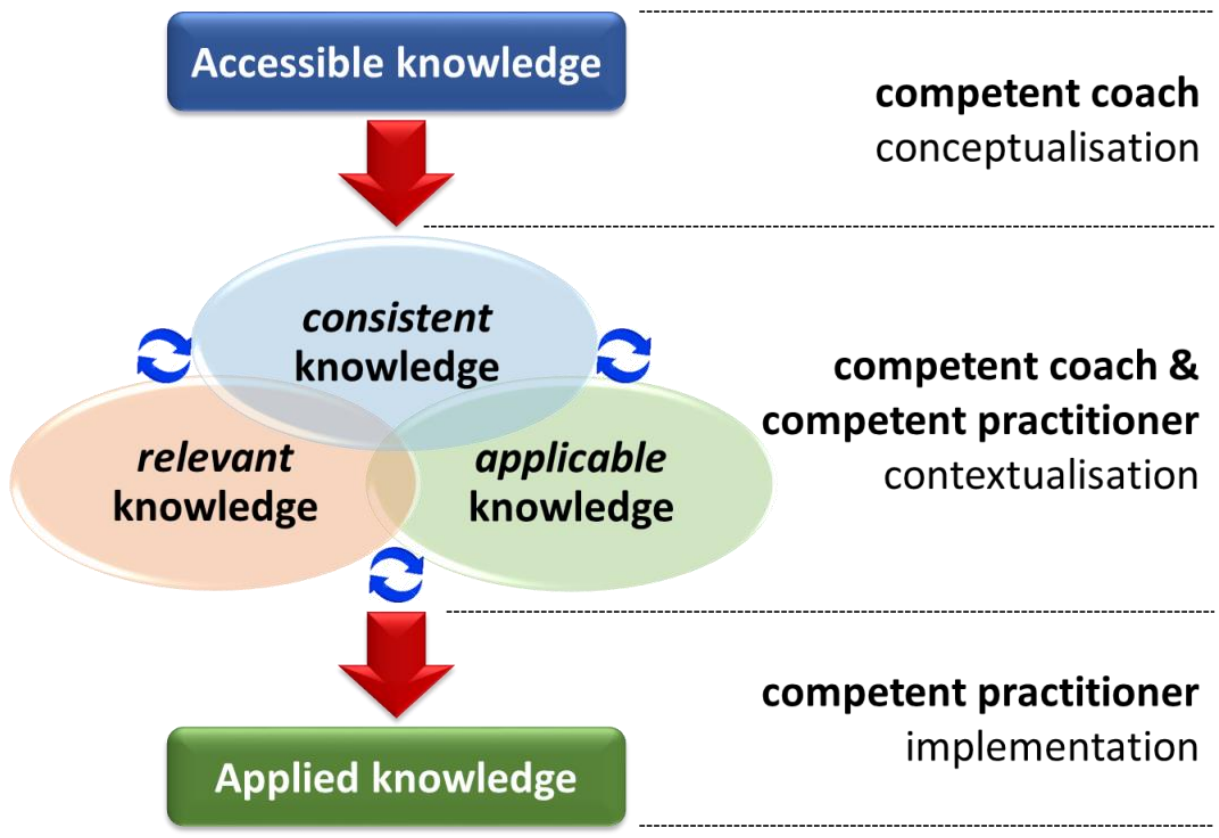

Figure 3: The refined conceptual framework of competent coaching

So far we have not delved into any details of what happens after the contextualisation process is completed, i.e. what happens with the applicable knowledge? At a high level of abstraction this is simple: the applicable knowledge gets implemented, and thus it becomes applied knowledge. In reality, there is nothing simple about implementing the applicable knowledge. The reason that we do not intend to cover it in this paper is that the coach may or may not participate in this final phase and implementation is not part of what we call 'knowledge engineering' (even if the coach continues to work with the coachee, it will be a very different type of coaching work than the contextualisation). It still belongs under competent coaching, as it needs both a competent coach and a competent coachee, but it will typically involve a number of people that the coachee needs to interact with. Very often, however, the implementation happens after the coach has finished her/his work. 


\section{Concluding Remarks}

In order to make our conceptual framework as robust as possible, we applied the same sort of validation process that we used to explain the contextualisation process of competent coaching. First, to validate the consistency, we have examined the emerging framework from every angle we could; we have done this repeatedly, having different knowledge in mind. This process corresponds to building the knowledge base and constantly revising it in knowledge engineering. It lasted for several years and helped us to achieve a sufficiently high level of consistency. Then, we removed many concepts without which the framework could be still understood and we tested the relevance of the framework in our teaching about both coaching and knowledge-based expert systems as well as through thoughtprovoking discussions. This corresponds to looking at the complex rules in knowledge engineering. Finally, to validate the applicability of our framework, we have gone through a reflexive process of recalling our coaching experiences in which we exposed "contradictions, doubts, dilemmas, and possibilities" and thus complexified our thinking about the process of competent coaching (Cunliffe, 2002). In order to enrich our perspectives on these coaching cases, we also discussed our emerging conceptual framework with some of our former coachees, which naturally led to further polishing of our framework. Examining our coaching experiences from a variety of perspectives corresponds to applying the rules to particular decision alternatives in knowledge engineering. This means that we have covered all three validation phases of the contextualisation process. Now, our aim is to reach the fourth level of validation that is never used for validating particular knowledge bases, since knowledge bases are built for particular decision problems. In contrast, we are interested in a wider use of our conceptual framework, and thus we are presenting it to colleagues, coaches, practitioners and academics alike, in hopes of sparking a discussion and receiving additional experiential (dis) confirmation as a form of intersubjective validation.

\section{References}

- Anzai, Y \& Simon, HA (1979) The Theory of Learning by Doing, Psychological Review, 86(2): 124-140, CrossRef

- Baracskai, Z, Dörfler, V \& Velencei, J (2005) Majstor i kalfa (Master and Apprentice), Sinergija, Zagreb, Croatia.

- Baracskai, Z, Dörfler, V \& Velencei, J (2007) The ES Could Probably Know More - But Man Would Not Make Better Business Decisions, VIPSI 2007 Bled, 8-11 October, 2007, Bled, Slovenia.

- Cheetham, G \& Chivers, G (1998) The reflective (and competent) practitioner: a model of professional competence which seeks to harmonise the reflective practitioner and competence-based approaches, Journal of European Industrial Training, 22(7): 267-276, CrossRef

- Chia, RCH (2014) Reflections on the distinctiveness of European management scholarship, European Management Journal, 32(5): 683-688, $\underline{\text { CrossRef }}$

- Cunliffe, AL (2002) Reflexive Dialogical Practice in Management Learning, Management Learning, 33(1): 35-61, CrossRef

- Cunliffe, AL \& Coupland, C (2012) From Hero to Villain to Hero: Making Experience Sensible through Embodied Narrative Sensemaking, Human Relations, 65(1): 63-88, CrossRef

- Dorfler, V (2010) Learning Capability: The Effect of Existing Knowledge on Learning, Knowledge Management Research \& Practice, 8(4): 369-379, CrossRef

- Dorfler, V \& Ackermann, F (2012) Understanding Intuition: The Case for Two Forms of Intuition, Management Learning, 43(5): 545-564, CrossRef

- Dorfler, V, Baracskai, Z \& Velencei, J (2015) Mashup Content for Passionate Learners: Bridge between Formal and Informal Learning, M Herzog Economics of Communication: ICT Driven Fairness and Sustainability for Local and Global Marketplaces, GITO Verlag, Berlin, Germany: 105-129.

- Dorfler, V \& Eden, C (2014) Research on Intuition using Intuition, M Sinclair Handbook of Research Methods on Intuition, Edward Elgar Publishing, Cheltenham, UK: 264-276, CrossRef

- Drucker, PF (1981) Why Management Consultants? [Electronic Version]. Knowledge at Work from

- Ehrenzweig, A (1967) The Hidden Order of Art: A Study in the Psychology of Artistic Imagination, University of California Press, Berkeley, CA.

- Kuhn, TS (1962/1996) The Structure of Scientific Revolutions (3rd ed.), The University of Chicago Press, Chicago, IL. https://books.google.co.uk/books?id=xnjS401VuFMC 
- Nicolescu, B (2010) Methodology of Trans-disciplinarity: Levels of Reality, Logic of the Included Middle and Complexity, Trans-disciplinary Journal of Engineering \& Science, 1(1): 19-38.

- Nicolescu, B (2014) Methodology of Trans-disciplinarity, World Futures, 70(3-4): 186-199, CrossRef

- Nicolescu, B (2016) Hidden Third, Quantum Prose, New York, NY.

- Piaget, J (1972) L'épistémologie des relations interdisciplinaires (The Epistemology of Interdisciplinary Relations), L Apostel, G Berger, A Briggs \& G Michaud Interdisciplinarity: Problems of Teaching and Research in Universities ; Based on the Results of a Seminar on Interdisciplinarity in Universities Organised by CERI in Collaboration with the French Ministry of Education at the University of Nice (France) September 7th - 12th, 1970, OECD. [PublishedinFrench]

- Prusak, L \& Davenport, TH (2003) Who Are the Gurus' Gurus?, Harvard Business Review, 81(December): 14-16.

- Schon, DA (1983) The Reflective Practitioner: How Professionals Think in Action, Basic Books, New York, NY.

- Schon, DA (1987) Educating the Reflective Practitioner: Toward a New Design for Teaching and Learning in the Professions, Jossey-Bass, San Francisco, CA.

- Senge, PM, Kleiner, A, Roberts, C, Ross, R, Roth, GL \& Smith, B (1999) The Dance of Change: The Challenges to Sustaining Momentum in Learning Organization, Doubleday Currency, New York, NY.

- Stierand, M (2013) Gastronomy and Haute Cuisine, RC Wood Key Concepts in Hospitality Management SAGE Publications, London, UK: 50-54.

- Stierand, M (2015) Developing Creativity in Practice: Explorations with World-Renowned Chefs, Management Learning, 46(5): 598-617, CrossRef

- Stierand, M \& Dörfler, V (2014) Researching Intuition in Personal Creativity, M Sinclair Handbook of Research Methods on Intuition, Edward Elgar Publishing, Cheltenham, UK: 249-263, CrossRef

- Stierand, M \& Dörfler, V (2016) The Role of Intuition in the Creative Process of Expert Chefs, Journal of Creative Behavior, 50(3): 178-185, $\underline{\text { CrossRef }}$

- Stierand, M, Dörfler, V \& MacBryde, J (2014) Creativity and Innovation in Haute Cuisine: Towards a Systemic Model, Creativity and Innovation Management, 23(1): 15-28, CrossRef

- Stierand, M \& Lynch, P (2008) The Art of Creating Culinary Innovations, Tourism and Hospitality Research, 8(4): 337-350, CrossRef

- Stierand, M \& Sandt, J (2007) Organising Haute-Cuisine Service Processes: A Case Study, Journal of Hospitality and Tourism Management, 14(1): CrossRef

- Stierand, M \& Zizka, L (2015) Reflecting on Hospitality Management Education through a Practice Lens, Quality Assurance in Education, 23(4): 353-363. CrossRef

- Velencei, J, Baracskai, Z \& Dörfler, V (2015) Educating the Trans-disciplinary Mind: Curriculum Design for a Professional Doctorate, EDULEARN 2015, 6-8 July 2015, Barcelona, Spain: 2769-2776.

- Velencei, J, Dörfler, V, Baracskai, Z \& Szendrey, J (2015) Prelude for Experience Mining (Re-)Using Relevant Experience for Smart Decision Support, International OFEL Conference on Governance, Management and Entrepreneurship, Dubrovnik, Croatia: 558-562.

- Weick, KE (1979) The Social Psychology of Organizing (2nd ed.), McGraw-Hill, New York, NY.

- Weick, KE (1995) Sensemaking in Organizations, Sage Publications, Thousand Oaks, CA. 